\title{
Health Sciences Online: Eight+ Revolutions and Ten+ Brief Analyses
}

\author{
Erica Frank* \\ University of British Columbia, 5804 Fairview Avenue, Vancouver, BC, V6T 1Z3, Canada
}

\begin{abstract}
:
Objective: There are many outstanding computer-based resources for medical education, but good materials are difficult to find in the flood of mediocre and questionably-sourced resources, and many good materials are currently passwordprotected. This article introduces a potential solution to many of these problems: Health Sciences Online (www.hso.info).
\end{abstract}

Method: A qualitative description of a new learning tool, and the societal changes it could precipitate.

Results: HSO is the only health sciences website with comprehensive, free, high-quality, ad-free, and current courses, references, and other resources. HSO already includes $>50,000$ such resources, but it is not just a huge, screened online library. We outline eight potential revolutionary areas for HSO: health sciences education, disease surveillance, public health ethics, integrity, needs assessments, telemedicine, local professional opportunities, and funding. HSO also responds to the World Health Organization's March 2008 "10 Facts on Health Workforce Crisis," and we briefly analyze these facts and HSO's responses in our concluding analysis section.

Conclusion: HSO has the potential to revolutionize health sciences knowledge, as well as multiple other areas in medicine, public health, and other health professions.

The problem: there are many outstanding computerbased resources for health sciences education, but good materials are difficult to find in the flood of mediocre and questionably-sourced resources, and many good materials are currently password-protected.

This article comments on a solution to some of these problems: Health Sciences Online. HSO is the only health sciences website (www.hso.info) with comprehensive, free, high-quality, ad-free, and current courses, references, and other resources. HSO already includes $>50,000$ such resources, searchable in and with text translated into 22 languages, but it is not just a huge, screened online library. Below we outline eight potential revolutionary areas for HSO: health sciences education, disease surveillance, public health ethics, integrity, needs assessments, telemedicine, local professional opportunities, and funding. HSO also responds to the World Health Organization's March 2008 "10 Facts on Health Workforce Crisis," [1] and we briefly analyze these facts and HSO's responses in our concluding analysis section.

HSO is a virtual learning center designed for health scientists in training and practice, founded in 2001 (by the author) and officially launched in 2008. It provides browsable and searchable access to materials donated, hosted, and maintained by our distinguished content partners. Founding collaborators and funders for this site include WHO, World Bank, NATO, the Canadian government, US Centers for Disease Control and Prevention, the World Medical Association, and others, with materials and collaborations from governments, professional societies, businesses,

*Address correspondence to this author at the University of British Columbia, 5804 Fairview Avenue, Vancouver, BC, V6T 1Z3, Canada;

E-mail: efrank@emory.edu and universities such as Columbia, Cornell, Emory, Harvard, Johns Hopkins, MIT, the University of British Columbia, and thousands of others. While other open source (and many for profit) health science information sites exist, HSO uniquely includes most of the high quality electronic learning objects that are ad-free and freely available across the health sciences. It also includes resources previously unavailable to the public that were directly obtained from universities and other scientific organizations providing accredited continuing education. Additionally, all our materials were individually screened by health professionals to include only resources that are relevant to the health sciences, independently useful as a teaching or learning tool, from a credible source that is accredited for health provider education, free of advertising, current, user-friendly, and cost-free to our users.

\section{HEALTH SCIENCES EDUCATION AND TRAINING}

Through HSO, the entire computerized world has free access to a comprehensive collection of top quality courses and references in medicine, public health, dentistry, pharmacy, nutrition, and other basic and clinical disciplines. Those with only occasional online or flash drive access can download materials for subsequent use. There is also free and compatible access through mobile phones.

WHO's 2006 “Building Foundations for E-Health" stated that "HSO is expected to make a significant contribution to global collaborations on e-learning [2];" we hope that education and training will be the first HSO-based revolution, and will produce more trained health care workers for underserved populations; to that end, we are developing a community-based health sciences university.

Specifically, here are two examples of active partnerships to promote HSO's use that are already underway. Working 
through a NATO Science for Peace grant to HSO, Armenian and Georgian physicians have received needs assessments, and they are receiving training on using $\mathrm{HSO}$ in their work settings, with feedback to HSO staff to refine this tool and its usage, including creating new physician training programs. And with Latin American partners, we are designing public health and medical curricula with dozens of courses and hundreds of references to choose from, and creating virtual educational and training programs.

\section{DISEASE SURVEILLANCE}

We are also modernizing outbreak and chronic disease surveillance. Our search engine (Vivisimo) logs search terms (automatically translatable into ICD disease coding), and can identify internet provider, and latitude and longitude for every search entry. Our survey/feedback feature allows instantaneous communications with searchers entering unusual terms about the nature of their queries. For example, someone querying symptoms consistent with cutaneous anthrax could be asked a pre-programmed series of questions, such as "Are you currently seeing patients with these symptoms?" We will therefore be able to create a customized alert system to pinpoint, screen, and flag potential outbreaks, while protecting patient privacy (see below). We can also automatically and cooperatively communicate this information to the WHO, CDC, Public Health Agency of Canada, or any of the other 50 members of the International Association of $\mathrm{Na}$ tional Public Health Institutes. To complement this, clinicians could upload radiographic and dermatologic images, pathologic slides, and other data, with their location identified. These findings can be geo-mapped with graphics visually representing diseases and their locations, intensity, and patterns over time. We believe that these functions will help modernize surveillance, and understand that Google Flu and CDC will also share claims of primacy in these kinds of efforts later this year.

\section{PUBLIC HEALTH ETHICS}

Once we institutionalize the kind of disease surveillance described in the paragraph above, we need to respond to the associated ethical issues. Is it ethical to gather this sort of information on people without their explicit consent (it certainly is done all the time for commercial reasons)? Is it ethical not to do this sort of intervention when it has the potential to inexpensively, efficiently, and beneficently save millions of lives? We will work to resolve these issues with UBC's Canada Research Chair in Neuroethics Judy Illes, $\mathrm{PhD}$, and others. We will help define how to best reconcile, in an electronic age, patient privacy and our opportunities and duties to protect.

\section{INTEGRITY}

Many post-Soviet countries (and others with transitional/developing economies) have poorly-developed systems for continuing medical education (CME) and CME licensing/accreditation. Courses are often very difficult to access for rural practitioners, creating a market for privileged and well-connected practitioners to obtain certificates without necessarily attending trainings. HSO can help institutionalize a better system by making CME, courses, trainings, and tests easily available and free of cost.

\section{NEEDS ASSESSMENTS}

We are able to list the most searched terms in any town, region, or country in the world; this is an automated mechanism for determining high priority knowledge and training needs in health. We can also produce automated gap analyses, with tallies of the most searched keywords that produce poorly matching results. These could be available in real time on HSO.info, encouraging content creators around the world to offer needed materials to HSO to be screened for inclusion, and allowing our volunteers/staff to search for such materials. Health sciences educational needs assessments could evolve from a laborious and expensive process toward one that is automated and efficient. For those interested in educating and training any kind of health professional, anyplace in the world, this will be a new and powerful tool.

\section{TELEMEDICINE}

We can make telemedicine available at any site with a video camera or an image capturing cell phone. For example, in places where there are insufficient health providers or appropriate specialists, one could obtain and transmit images of a lesion to a dermatologist to help diagnose and make recommendations for follow-up. And practitioners could videoconference with each other, consulting HSO reference materials, and creating virtual medical and public health communities. This is not an ideal way to practice medicine, nor is telemedicine unique to HSO, but it is likely better than the current vacuum in many locations, and the infrastructure of HSO could support it unusually well. We believe that HSO could help spread such new diagnostic techniques (as well as the corresponding prevention and treatment techniques).

\section{LOCAL PROFESSIONAL OPPORTUNITIES}

HSO increases local capacity building by making outstanding training and education as close as the nearest mobile phone, laptop, or internet café. But in addition, we can build capacity by spidering health sciences job listing sites on the searcher's continent, or displaying appropriate volunteer opportunities, or posting sites for medical meetings in a confined radius; we could restrict our searching to those regions in order to decrease brain drain, and to reduce greenhouse gas emissions from travel to medical conferences by making users aware of local options. We believe that this could help fill needed positions (perhaps even with HSOtrained providers), and could reduce our global greenhouse gas footprint (US healthcare organizations spend $\$ 8.3$ billion yearly on energy) [3]. This will help level the intellectual and greenhouse gas playing fields between the usually neglected people of less developed countries and the consumeremitters of industrialized countries.

\section{FUNDING}

HSO's support to date has come primarily from volunteer efforts and individual donations, with some additional funding already received from WHO, NATO, and the Canadian government. While we are not opposed to revenue, we will be able to sustain HSO without any external funding, if need be, in perpetuity; HSO is created by health professionals who do this work because we believe it will save and improve 
many millions of lives every year. Others have tried to create similar products (some of which we include among our spidered resources), using for-profit business models, with less success. We aspire to move from a world with expensive and difficult-to-navigate walls around health information toward a democratization of knowledge and the hope of health for all. And we say eight+ instead of eight revolutions because additional and unprecedented applications of HSO occur to our collaborators on a frequent basis, and we suspect that we and our users will develop other important and novel ways to use this tool.

\section{ANALYSES}

In March 2008, the WHO outlined "10 Facts on Health Workforce Crisis [1]". We believe that HSO helps address many of these 10 facts and summarize them below (with their numbers listed in parentheses) and with HSO's responses:

The 60 million health workers in the world are effective, but (2) there are 57 countries with a critical health shortage, and (3) we need at least 4.2 million additional health workers.

It is clear that we need to create many more health workers than can be produced using current mechanisms, and that our ongoing failure to do so means that many people unnecessarily suffer and die. HSO provides immediate, free access for policy makers, academicians, and practitioners to have the educational means to increase the numbers of well-informed health workers.

(4 and 5) Contrasts between Sub-Saharan Africa and the Americas are especially stark and (6) disparities in economics and in the ability to respond to pandemics generally favor consumer/carbon-emitter nations.

Table 1. Americas vs. Africa Comparison

\begin{tabular}{|c|c|}
\hline North/South America & Sub-Saharan Africa \\
\hline \hline $14 \%$ of population & $11 \%$ of population \\
\hline $10 \%$ of disease burden & $25 \%$ of disease burden \\
\hline $37 \%$ of health workers & $3 \%$ of health workers \\
\hline$>50 \%$ of health expenditure & $<1 \%$ of health expenditure \\
\hline
\end{tabular}

North America benefits enormously from our disproportionate share of health and other resources. By collecting and cataloguing much of the outstanding health worker educational materials produced here (and in other countries, where available), HSO provides a significant opportunity to narrow the gap.

We need to use more innovative methods to train more clinicians, and to train them faster and (9) a relatively conventional approach to rapidly scaling up the number of clinicians would average US $\$ 447$ million per country per year.

While HSO requires some infrastructure, personnel, and other resources to train clinicians, it requires far fewer resources than conventional educational modalities, and can train rapidly; our planned HSO-based virtual health sciences university will help address these needs.

(8) Health worker migration is increasing.

While some brain-drain contributors cited by WHO (such as wages) are beyond HSO's control, others such as working conditions and career opportunities are improved by increasing local educational and service opportunities with our educational and diagnostic tools.

(10) These health worker efforts must be transdisciplinary.

HSO's materials are browsable by discipline. But since materials are also searchable, HSO encourages users to explore transdisciplinary sources. To use a few diabetes examples:

- A continuing education course categorized under pharmacy [4] provides text and exam questions on improving glycemic control that could be useful for pharmacists, but also for physicians or nurse practitioners in training or practice.

- An Italian university's biochemical insulin overview could help nursing, nutrition, medical, or biochemistry students [5].

- The National Institutes of Health's "Working together to manage diabetes: a guide for pharmacy, podiatry, optometry, and dental professionals" crosses at least four disciplines [6].

- An electronic book from the National Library of Medicine provides an introduction for any health scientist to "The Genetic Landscape of Diabetes" [7].

- Virginia Commonwealth University's "Insights into Drug Treatments for Diabetes" [8] is "designed to provide any medical or allied health professional with advanced information to improve their care of older adults."

And finally, from Dr. Neil Pakenham-Walsh, coordinator of the Healthcare Information For All by 2015 campaign (www.hifa2015.org), an $11^{\text {th }}$ critical fact [9]: The needs of existing health workers have been ignored for too long. These needs include information and other electronically deliverable resources, and HSO is already working with individuals, governments, and funders to help bring these materials to those now in the field.

In seven years, and with the aim of achieving these eight+ revolutions and ten+ answers, HSO has become a global resource because people have said "I think this is a good idea, and here's how I could help." We encourage learners, educators, funders, governments and other potential collaborators to use www.HSO.info, give us feedback, and join us in its further development.

\section{SOURCES OF SUPPORT}

Funding for this project has been provided by the Canada Research Chair program, the Michael Smith Foundation for Health Research, BC Knowledge Development Fund, Ulrich 
and Ruth Frank Foundation for International Health, and Canada Foundation for Innovation.

\section{ACKNOWLEDGEMENTS}

I would like to acknowledge the guidance, dedication, and invaluable work of our core team on HSO: Kshamica Nimalasuriya, MD, MPH; Kate Tairyan, MD, MPH; Ann Hulton; Artak Stepanyan, MD; Michelle Wruck, Carolina Segura, MD; Randall White, MD; and Nathaniel Etheridge Frank-White.

\section{REFERENCES}

[1] World Health Organization. 10 Facts on Health Workforce Crisis [online]. 2008, Mar 3 [cited 2008 March 16]. Available from: http://www.who.int/features/factfiles/health_workforce/en/index.ht $\mathrm{ml}$

[2] World Health Organization. Building Foundations for E-Health; 2006: 63 [cited 2008 March 16]. Available from: http://www.who. int/goe/publications/bf_FINAL.pdf

[3] U.S. Environmental Protection Agency, U.S. Department of Energy. ENERGY STAR for Healthcare [online]. [Cited 2008 March 16]. Available from: http://www.energystar.gov/index.cfm?c= healthcare.bus_healthcare
[4] Power Pak CE. Improving glycemic control by minimizing blood glucose variability [online]. [Cited 2008 March 16]. Available from: http://www.powerpak.com/index.asp?show=lesson\&page= courses/105292/lesson.htm\&lsn_id=105292

[5] King MW, Marchesini S. Insulin Function And Diabetes [online] 2007, [cited 2008 March 16]. Available from: http://www.med. unibs.it/ marchesi/diabetes.html

[6] National Diabetes Education Program, NIH. Working together to manage diabetes: a guide for pharmacy, podiatry, optometry, and dental professionals [online]. 2007 May, [cited 2008 March 16] Available from: http://www.ndep.nih.gov/diabetes/pubs/ppodprimer_color.pdf

[7] National Library of Medicine, NIH. The Genetic Landscape of Diabetes [online]. 2004, [cited 2008 March 16]. Available from: http://www.ncbi.nlm.nih.gov/books/bv.fcgi?rid=diabetes.TOC\&de pth $=1$

[8] Sisson E. Sweet Success: Insights into Drug Treatments for Diabetes [online]. 2003, [cited 2008 March 16]. Available at http://www.virginiageriatrics.org/grounds/vgc/lecture.php?lecture= 508

[9] Pakenham-Walsh, N. Posting to www.hifa2015.org regarding "WHO: 10 Facts on Health Workforce Crisis;" posted and [cited 2008 March 16].

(C) Erica Frank; Licensee Bentham Open

This is an open access article licensed under the terms of the Creative Commons Attribution Non-Commercial License (http://creativecommons.org/licenses/by-nc/3.0/) which permits unrestricted, non-commercial use, distribution and reproduction in any medium, provided the work is properly cited. 